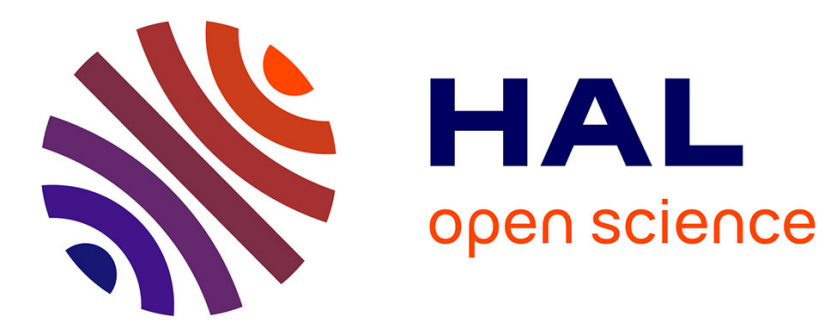

\title{
Fostering computer supported collaborative learning with cooperation scripts and scaffolds
}

\author{
Armin Weinberger, Frank Fischer, Heinz Mandl
}

\section{To cite this version:}

Armin Weinberger, Frank Fischer, Heinz Mandl. Fostering computer supported collaborative learning with cooperation scripts and scaffolds. International Conference on Computer Support for Collaborative Learning - CSCL 2002, 2002, Boulder, United States. 2 p. hal-00190172

\section{HAL Id: hal-00190172 \\ https://telearn.archives-ouvertes.fr/hal-00190172}

Submitted on 23 Nov 2007

HAL is a multi-disciplinary open access archive for the deposit and dissemination of scientific research documents, whether they are published or not. The documents may come from teaching and research institutions in France or abroad, or from public or private research centers.
L'archive ouverte pluridisciplinaire HAL, est destinée au dépôt et à la diffusion de documents scientifiques de niveau recherche, publiés ou non, émanant des établissements d'enseignement et de recherche français ou étrangers, des laboratoires publics ou privés. 


\title{
Fostering computer supported collaborative learning with cooperation scripts and scaffolds
}

\author{
Armin Weinberger, Frank Fischer, \& Heinz Mandl
}

\author{
Institute of Educational Psychology, Ludwig-Maximilians-University of Munich, \\ Leopoldstr. 13, 80802 Munich \\ weinberg@edupsy.uni-muenchen.de, \\ fischerf@edupsy.uni-muenchen.de, \\ mandl@edupsy.uni-muenchen.de
}

\begin{abstract}
The study investigates collaborative learning of small groups via text-based computer-mediated communication. We analyzed how two approaches to pre-structure communication influence participation, individual knowledge transfer, the convergence of participation and the convergence of knowledge among peers. We varied the factor scripted cooperation and the factor scaffolding in a 2x2-design. 105 university students of Educational Psychology participated. Results show that scripted cooperation was most and scaffolding least beneficial to individual transfer, knowledge convergence and participation in comparison to open discourse.
\end{abstract}

\section{Keywords}

CSCL, knowledge convergence, shared knowledge, participation, scripted cooperation, scaffolding, cues, cued interaction, computer-mediated communication, text-based communication, case-based learning environments

\section{BACKGROUND AND GOALS OF THE STUDY}

In collaborative, problem-oriented learning environments groups of learners are supposed to discuss and solve cases in an active and reflective way. However, learning in open discussion rarely seems to result in equal and high participation and equally distributed high individual transfer. Studies on CSCL show that these negative effects are usually replicated or even increased in new, technology-rich learning environments (e.g. Fischer \& Mandl, 2001). This study investigates instructional means (scripted cooperation and scaffolding) to support participation and individual transfer of knowledge in case-based CSCL environments. Moreover, we analyze to what extent convergence of participation and convergence of knowledge of the learning partners can be fostered in CSCL.

Text-based, computer-mediated communication offers the possibility to structure the learners' discourse and can be designed to guide users through certain successive activities (Scardamalia \& Bereiter, 1996). Scaffolding and scripted cooperation can be implemented with cues that have been previously inserted into messages of learners in order to pre-structure communication and possibly influence reflection and thereby also learning outcomes. These methods may substitute extensive training and adaptive feedback by co-present experts. On this background, the study investigates the effects of cued scaffolding and scripted cooperation and their combination with regard to (1) participation and the convergence of participation within a learning group and (2) the individual knowledge transfer and knowledge convergence.

\section{METHOD}

After a pre-test including a problem case participants of all conditions of the 2x2-design were asked to individually study a three page description of attribution theory, which is standard curriculum content. After this individual phase, the learners worked together on three cases communicating via a web-based discussion board in which the cued scaffolding and the cued cooperation script were implemented (see figure 1). The collaboration was followed by an individual post-test that included another case. Time-on-task was 3 hours in all four conditions.

Cues of scaffolding and of cooperation script were automatically inserted into the messages of the learners. The cues of scaffolding were questions about the case. Thus, the students' task was basically to respond and jointly elaborate on the given cues. The cues of the scripted cooperation was supposed to support students to take over the role of an analyzer for one of the three cases and the role of a critic for the remaining two cases.

Collected data include learning prerequisites (motivation, interest, anxiety, etc.), participation (e.g. words produced), participation convergence (similarity of participation inside one group), individual knowledge transfer (inferences of 
theoretical concepts on case information) and knowledge convergence (sum of shared inferences, i.e. inferences which two or three participants of one group had in common in the individual transfer case).
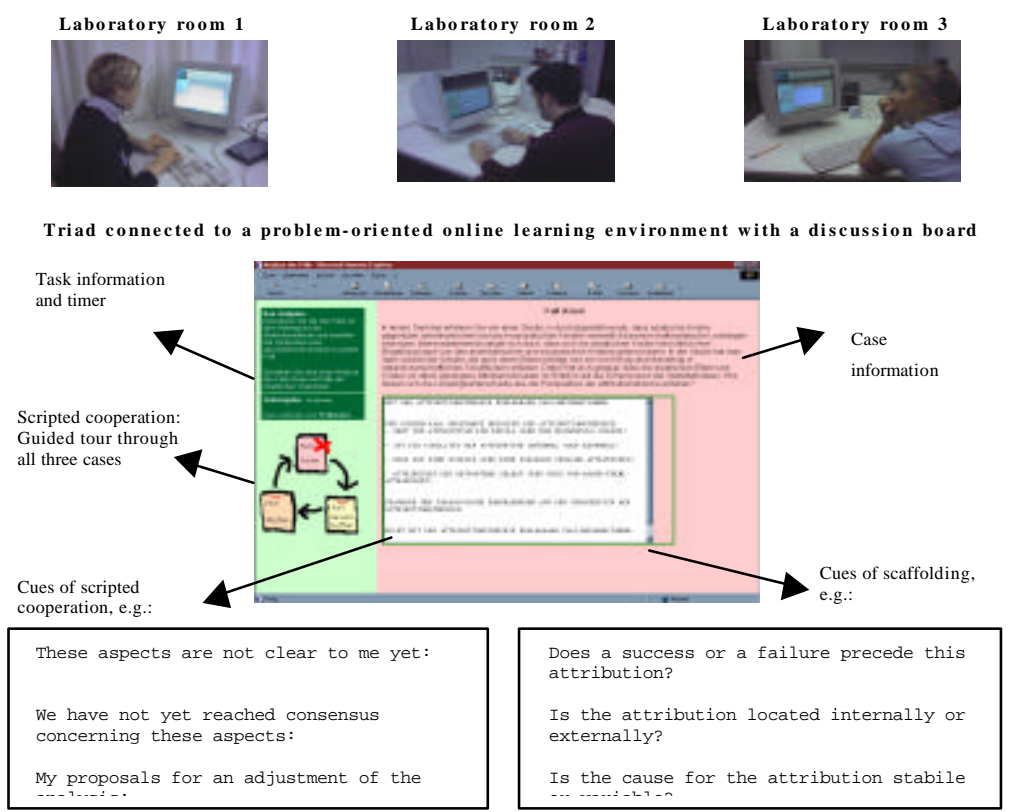

Figure 1: The experimental setup and the online learning environment. In the upper part you can see three participants in separate rooms communicating via a discussion board that is illustrated in the lower part.

\section{RESULTS AND CONCLUSIONS}

The findings show that participation, participation convergence, individual knowledge transfer and convergence of knowledge can be influenced not only by the preliminary training and moderation of collaborative learning, as studies have shown before, but also by the cue-based implementation of scripted cooperation and scaffolding into an online learning environment that structures the learning discourse itself.

The cued cooperation script proved to support learners substantially in comparison to open discourse regarding participation, convergence of participation, individual knowledge transfer and knowledge convergence. It was possible to replicate the positive effects of former research on scripted cooperation with scripted cooperation implemented with cues. Learners appeared to be encouraged to confront their ideas with those of their partners, reflect on the differences of perspectives, and sometimes modify their initial point of view.

A cued scaffolding of problem-oriented collaborative learning did not show substantial effects on participation or participation convergence, but was significantly least beneficial to the individual knowledge transfer and knowledge convergence in comparison to the other treatments. Maybe, the scaffolding did not foster the transfer as effectively as the other treatments, since important processes of learning failed to take place. Like a checklist, it may have facilitated the identification of relevant problems and their solution during the collaborative phase, but did not support the participants in developing a conceptual understanding of their own. Consequently, an integral part of scaffolding should be the fading of this kind of support. Maybe the scaffolding rather fostered individual than collaborative approaches to solve the cases. A joint effort to reflect on the application of theoretical concepts to case information may not have appeared relevant to the learners, as the scaffolding suggested an individual approach to solve the cases. We are currently investigating the discourse regarding collaborative knowledge construction in order to confirm or reject these hypotheses.

\section{REFERENCES}

Fischer, F., \& Mandl, H. (2001). Facilitating the construction of shared knowledge with graphical representation tools in face-to-face and computer-mediated scenarios. In P. Dillenbourg, A. Eurelings, \& K. Hakkarainen (Eds.), Proceedings of euro-CSCL 2001 (Maastricht, NL, March 2001), 230-236.

Scardamalia, M., \& Bereiter, C. (1996). Computer support for knowledge-building communities. In T. Koschmann (Ed.), CSCL: Theory and practice of an emerging paradigm (pp. 249-268). Erlbaum, Mahwah, NJ. 